https://orcid.org/0000-0001-6444-2631

\title{
Sociedade Limitada: Algumas das Principais DifERENÇAS ENTRE AS LEGISLAÇÕES BRASILEIRA E ESTADUNIDENSE ${ }^{1}$
}

\author{
Leonardo Netto Parentoni*
}

\begin{abstract}
1 Objetivo do artigo e método. 2 Diferenças fundamentais entre os sistemas jurídicos brasileiro e estadunidense. 3 Breve histórico legislativo das sociedades limitadas no Brasil e nos Estados Unidos. 4 Algumas das principais diferenças entre as legislações brasileira e estadunidense sobre sociedades limitadas. 4.1 Constituição. 4.2 Administração e controle. 4.3 Direitos e obrigações. 4.4 Transferência de participações societárias. 4.5 Dissolução parcial e total. 5 Conclusão. Referências.
\end{abstract}

\section{RESUMO}

O presente artigo traça um paralelo entre a sociedade limitada no Brasil e nos Estados Unidos, a partir de uma perspectiva regulatória, com base em estudo comparativo de legislações: o Código Civil, no Brasil, e a Lei Revisada Uniforme das Sociedades Limitadas - Revised Uniform Limited Liability Company Act (RULLCA), nos Estados Unidos. O escopo do trabalho é destacar algumas das principais diferenças entre esses sistemas jurídicos quando tratam do mesmo tema. Por fim, espero que este estudo ajude a identificar os prós e os contras do cenário regulatório das sociedades limitadas em ambos os países, o que pode ser útil na reavaliação e na alteração de suas leis.

Palavras-chave: Sociedade Limitada (LTDA). Limited Liability Company (LLC). Legislação Comparada.

\section{OBJETIVO DO ARTIGO E MÉTODO}

O objetivo do presente artigo é traçar um paralelo entre a sociedade limitada no Brasil e nos Estados Unidos, chamada de Limited Liability Company (LLC), a partir de uma ótica regulatória, destacando algumas das principais diferenças na maneira como as leis uniformes desses países lidam com a mesma questão. Como mencionado, o artigo enfoca as sociedades limitadas, não abordando sociedades por ações ou qualquer outro tipo societário.

Esta seção explica o método que guiou a pesquisa e o escopo do artigo. A seção 2 explica o que é uma sociedade limitada e algumas diferenças fundamentais entre os sistemas jurídicos brasileiro e estadunidense. A seção 3 traz um breve histórico da introdução e do desenvolvimento da legislação sobre sociedades limitadas em ambos os países. A seção 4 é o

* Doutor em Direito Comercial pela USP. Mestre em Direito Empresarial pela UFMG. Professor Adjunto da UFMG e titular do IBMEC/MG. Procurador Federal/AGU. Pesquisador Convidado na Universidade do Texas em Austin/EUA. E-mail: <parentoni@gmail.com>. http://orcid.org/0000-0002-3593-2831 
núcleo do artigo e analisa as diferenças entre as legislações mencionadas no que diz respeito: a) à constituição; b) à administração e ao controle; c) aos direitos e às obrigações; d) à transferência de participações societárias; e e) à dissolução parcial e total. $\mathrm{O}$ artigo conclui que, apesar de o Brasil possuir maior tradição com as sociedades limitadas, os Estados Unidos alcançaram notório desenvolvimento nesse tema, nas últimas décadas, inclusive superando as leis brasileiras em algumas das mais importantes questões. Atualmente, a sociedade limitada é um dos principais tipos societários nos dois países e tende a continuar sendo.

Em um futuro muito próximo (mais precisamente, no dia 10 de janeiro de 2019), o Brasil celebrará o centenário da adoção das sociedades limitadas pelo ordenamento jurídico pátrio. Além disso, 2017 marcou o vigésimo aniversário do paradigmático evento que fomentou o crescimento massivo das LLCs nos EUA, a chamada reforma tributária "check-the-box", de 1997. Destarte, é um momento especial para a realização de um estudo comparativo que pode ser útil para ambos os ordenamentos, quando forem reavaliar sua regulação sobre o tema. Em sintonia com esse propósito, o artigo foi cuidadoso ao contextualizar as várias questões de uma maneira que façam sentido não apenas para os leitores já familiarizados com ambos os ordenamentos jurídicos, mas também para qualquer interessado no assunto, ainda que em outros países. A intenção é tornar a discussão útil para um público mais amplo.

Seguindo um critério metodológico, ao longo do texto o padrão é mencionar primeiro as leis brasileiras para depois passar às estadunidenses, traçando um paralelo entre elas. Sempre mencionando os nomes das instituições estadunidenses em itálico. Isso porque o Brasil legislou sobre a sociedade limitada décadas antes dos EUA. Ademais, por essa mesma razão, o crescimento e o desenvolvimento desse tipo societário ocorreram primeiro no Brasil. Portanto, o artigo segue a ordem cronológica dos fatos. Isso não significa, por óbvio, que um sistema jurídico seja "melhor" ou "mais eficiente" do que o outro, tendo em vista que cada um deles tem suas próprias vantagens e falhas. Diante disso, esta foi apenas a escolha metodológica feita para garantir coerência e uniformidade ao longo do texto.

Assim sendo, o escopo deste artigo não é avaliar quais previsões legais funcionam melhor em uma perspectiva jurídica ou econômica, mas apenas delinear algumas das principais diferenças na forma como os dois países lidam com a mesma questão.

Outro critério é a abordagem de vários temas baseada apenas na legislação uniforme destes países acerca de sociedades limitadas: no Brasil, o Código Civil (de 2002); já os Estados Unidos possuem duas leis uniformes ${ }^{2}$ sobre sociedades limitadas: A Lei Uniforme de Sociedades Limitadas (The Uniform Limited Liability Company Act - ULLCA), de 1996, e a Lei Uniforme Revisada de Sociedades Limitadas (The Revised Uniform Limited Liability Company Act - RULLCA), de 2006, alterada por último em 2013. O presente artigo enfoca a lei norte-americana mais recente, a RULLCA. Segundo essa opção, a jurisprudência e as várias legislações estaduais dos EUA não são mencionadas. O motivo disso é que, no Brasil, uma única lei vem regendo as LTDAs em todo o território nacional, por quase um século. Nos Estados Unidos, por outro lado, esse tipo societário é mais recente. Sendo 
assim, diferentemente de outros tipos de associação para a consecução de negócios, como as partnerships ${ }^{3}$ e as companhias, ainda não há uniformidade legislativa sobre o tema em âmbito estadual. $\mathrm{O}$ mesmo se diga em relação às decisões judiciais. Nesse contexto, basear toda a pesquisa em uma legislação estadual específica dos EUA ou nas decisões do respectivo tribunal faria com que o artigo fosse perfeitamente adaptado àquele estado-membro, porém menos interessante ou, até mesmo, desnecessário para os vários outros estados-membros. ${ }^{4} \mathrm{O}$ foco na RULLCA supera esse problema porque se espera que ela se torne o modelo nacional para a harmonização ${ }^{5}$ das várias legislações estaduais. Desse modo, ela provê um parâmetro melhor para a comparação com a lei brasileira, porque ambas atuam em âmbito nacional.

Aliás, até 2016, apenas 19 dos 50 estados-membros dos Estados Unidos haviam adotado a ULLCA ou a RULLCA. ${ }^{6}$ Contudo, a tendência é que esse cenário mude no futuro, à medida que as LLCs continuem crescendo e se espalhando pelo país como um dos mais importantes tipos societários. O mesmo ocorreu no passado com as leis uniformes que tratavam das partnerships (agora adotadas em todos os estados-membros, com exceção de Louisiana) e com vários outros tipos societários. ${ }^{7}$

Em uma segunda fase, foi necessário delimitar ainda mais o escopo deste artigo. Com efeito, o Código Civil brasileiro e a RULLCA são muito extensos e complexos, com centenas de disposições em cada um. Então, por não ser recomendável (ou até possível) abordar todas essas previsões legais em um único artigo, este trabalho contempla apenas algumas questões principais, destacando as diferenças legislativas entre o Brasil e os EUA.

\section{DIFERENÇAS FUNDAMENTAIS ENTRE OS SISTEMAS JURÍDICOS BRA- SILEIRO E ESTADUNIDENSE}

Não seria correto apresentar uma pesquisa comparativa sem antes apontar as diferenças fundamentais entre os sistemas jurídicos analisados. Essas discrepâncias remontam aos distintos tipos de federação adotados em cada um dos países. Como já observado por um autor: "é impossível entender o sistema jurídico dos Estados Unidos sem antes entender a sua estrutura de governo.” (BURNHAM, 2006, p. 1). Na realidade, isso se aplica a todos os países.

No Brasil, o poder e a riqueza são extremamente concentrados na esfera federal (a União). ${ }^{8}$ A Constituição Federal claramente confere competência privativa à União para legislar sobre Direito Comercial. ${ }^{9}$ Destarte, o Brasil possui uma lei (o Código Civil) que regula as sociedades limitadas em todo o país. Nessa matéria, não são admitidas derrogações por lei estadual. ${ }^{10}$ Consequentemente, cada pessoa jurídica pode operar no país inteiro, não se aplicando o procedimento de qualificação do direito estadunidense (qualify for carrying on business outside the primary state of incorporation). A qualificação complementar apenas é exigida de sociedades estrangeiras. ${ }^{11}$

Nos Estados Unidos, por outro lado, os estados federados têm muito poder (ESTADOS 
UNIDOS DA AMÉRICA, 1789). Posto isso, cada estado pode editar suas próprias normas jurídicas regulando o funcionamento das sociedades nos limites de seu território. Cada estado federado tem, então, a sua própria lei de LLCs. ${ }^{12}$ De acordo com essa premissa, para exercer atividade econômica regularmente, fora do estado em que se situa a sede da pessoa jurídica, é necessário o procedimento de qualificação. Esse procedimento consiste em preencher um formulário e registrá-lo perante a autoridade competente ${ }^{13}$ de cada estado-membro em que a sociedade limitada deseja atuar. Diferentemente do que ocorre no Brasil, "sociedades estrangeiras" (foreign companies) nos EUA não são apenas as constituídas fora do país, mas também aquelas constituídas dentro dos Estados Unidos, porém em outro estado-membro. ${ }^{14}$

Talvez a maior diferença entre os países seja o fato de que, no Brasil, a legislação criou uma distinção artificial entre sociedade empresária e, por exclusão, os outros tipos de atividade econômica, chamados de sociedades simples (BRASIL, 2002). ${ }^{15}$ Essa classificação é artificial, uma vez que ambas desenvolvem atividade econômica. Na prática, as diferenças são o órgão de registro, bem como a recuperação judicial e a falência. Em praticamente todo o restante, elas operam da mesma maneira. A tributação também costuma ser semelhante. A referida classificação é tão artificial que tanto a sociedade simples quanto a empresária podem adotar o tipo de sociedade limitada (art. 983) (BRASIL, 2002), inclusive, salvo algumas profissões regulamentadas, como a advocacia, na prática, as demais sociedades simples adotam o tipo de sociedade limitada. Por causa dessa diferenciação, todas as pessoas jurídicas no Brasil precisam ter objeto social fixo e delimitado, devendo registrar imediatamente perante o órgão competente qualquer alteração no objeto. Nos Estados Unidos, simplesmente não existe essa distinção. Consequentemente, a sociedade limitada pode ser constituída para exercer "qualquer atividade lícita" (any lawful purpose).

Para finalizar essa breve introdução, vale mencionar que, no Brasil, todos os tipos societários precisam exercer atividade econômica, pois a própria definição de sociedade constante do Código Civil prevê essa prática como elemento do conceito de sociedade (art. 981) (BRASIL, 2002). Para atividades não econômicas, as opções são outras espécies de pessoa jurídica, como as associações (art. 53) ou fundações (art. 62) (BRASIL, 2002).

Enquanto isso, nos Estados Unidos, as várias espécies de sociedade (incorporated and unincorporated businesses) podem exercer atividade econômica ou não econômica (THE UNITED STATES OF AMERICA, 2017). Inclusive, uma mesma pessoa jurídica pode mesclar ambos os propósitos, como na "Sociedade Limitada de Baixo Lucro" (Low Profit LLC), ou, simplesmente, L3C. ${ }^{16}$ A estrutura e o Direito aplicável a uma L3C são praticamente os mesmos de uma sociedade limitada tradicional (LLC). Normalmente, a legislação sobre L3C é apenas um acréscimo às leis estaduais sobre sociedades limitadas, para incluir certas previsões específicas, tendo como principal diferença a prioridade que a L3C deve atribuir aos objetivos que sejam socialmente benéficos. Evidentemente, o lucro é bem-vindo, mas constitui objetivo secundário ao invés da principal razão para criar a pessoa jurídica. Esse tipo de sociedade atua como intermediário no levantamento de recursos para causas 
sociais. Esses recursos costumam vir principalmente de fundações privadas, por meio de Investimentos Relacionados a Programas (Program Related Investments - PRI), que se trata de investimentos de cunho religioso, educacional ou de caridade, tributariamente dedutíveis e feitos por fundações.

O problema é a falta de clareza das situações em que uma L3C estaria apta a receber PRIs. Essa incerteza está comprometendo o modelo e conduzindo à subutilização das L3C (BREWER, 2013), pois se trata de um tema bastante controverso na literatura jurídica estadunidense. Isso é comprovado nos estudos de alguns autores, tendo em vista que, enquanto uns afirmam que a L3C é "desnecessária e insensata" (unnecessary and unwise) (KLEINBERGER, 2010, p. 881), outros destacam justamente o oposto: a importância e a necessidade de aprimoramentos (WALKER, 2012). Certos autores dão um passo adiante de tais argumentos e sugerem que a agência estadunidense equivalente à Receita Federal do Brasil, Internal Revenue Service (IRS), reconheça a sociedade limitada sem propósito lucrativo (nonprofit LLC) como novo tipo societário, com tributação própria (SMITH, 2015, p. 1697).

\section{BREVE HISTÓRICO LEGISLATIVO DAS SOCIEDADES LIMITADAS NO BRASIL E NOS ESTADOS UNIDOS}

A sociedade limitada é um tipo societário que propicia tanto a limitação da responsabilidade de todos os sócios (independentemente de serem ou não administradores e/ou controladores da pessoa jurídica) quanto maior flexibilidade contratual do que nas sociedades anônimas. Além disso, nos EUA, é propiciado tratamento tributário bem mais favorável ao sócio do que nas sociedades anônimas. ${ }^{17}$ A literatura jurídica estadunidense a classifica como uma "criação contratual" (creature of contract), ao invés de "criação do legislador estadual" (statutory creation) (RIBSTEIN; KEATINGE, 2016). Em suma:

A sociedade limitada ('LLC') é uma estrutura de negócios diversa da sociedade anônima que propicia a seus titulares, chamados de 'sócios', algumas vantagens:

(1) responsabilidade limitada em relação às obrigações contraídas pela sociedade, mesmo quando o sócio é controlador; (2) vantagens tributárias (pass-through tax treatment); e (3) enorme liberdade contratual para estruturar os aspectos internos do empreendimento (HAMILTON; MACEY; MOLL, 2014, p. 1199). ${ }^{18}$

Suas características centrais são basicamente as mesmas no Brasil, nos EUA e no mundo todo. Claro que alguns tópicos são controversos, como os limites da flexibilidade contratual, especialmente quando utilizada para afastar a incidência de obrigações, prática comum no estado de Delaware. ${ }^{19}$ Todavia, enfatizar essas controvérsias não é objeto deste artigo.

Com efeito, a Alemanha foi o primeiro país a criar a sociedade limitada, em 20 de abril de 1892 (Gesellschaft mit beschränkter Haftung). O governo alemão planejava criar um tipo societário que combinasse a limitação de responsabilidade dos sócios, típica das sociedades anônimas, com maior flexibilidade contratual. Estudos conduzidos à época demonstraram que essa estrutura fomentaria o desenvolvimento de pequenas e médias empresas. O segundo 
país a adotá-la foi Portugal, em 11 de abril de 1901 (Sociedade por Quotas, de Responsabilidade Limitada). A partir de então ela começou a se espalhar pelo mundo, sempre conservando suas características fundamentais. ${ }^{20}$

Após declarar sua independência de Portugal, o Brasil promulgou o Código Comercial de 1850, com fortes influências do Código Comercial Francês, de 1807. O Código Comercial Brasileiro lidava principalmente com sociedades anônimas e empresários individuais, por serem as estruturas negociais mais comuns à época. Não havia, nesse Código, qualquer previsão sobre sociedades limitadas (FERREIRA, 1960). Décadas depois, o Decreto Federal $\mathrm{n}^{\mathrm{o}} 3.708$ introduziu o instituto no ordenamento brasileiro, em 10 de janeiro de 1919, com o nome de sociedade por quotas, de responsabilidade limitada. Esse decreto foi um dos textos mais duradouros do direito societário brasileiro, perdurando por mais de oito décadas, até meados de janeiro de 2003, sem sofrer qualquer alteração. Suas principais características eram a concisão (apenas 19 artigos), simplicidade (previsões muito claras) e flexibilidade (primazia da liberdade de contratar). A literatura jurídica e a jurisprudência paulatinamente preencheram suas lacunas (BORGES, 1959), e foi neste contexto que a sociedade limitada se tornou o tipo societário mais utilizado no Brasil.

Contudo, esse cenário passou por mudanças drásticas em 2003, quando entrou em vigor o Código Civil Brasileiro, promulgado em 10 de janeiro de 2002 (com um ano de vacatio legis). Essa lei implantou um modelo totalmente diferente para as sociedades limitadas, com várias regras cogentes que restringiram a liberdade de contratar e passaram a exigir complexas estruturas administrativas, além de prever confusas regras a respeito de quóruns de deliberação e outros temas, e, como já era de esperar, a literatura jurídica criticou fortemente as mudanças (PARENTONI; MIRANDA, 2016; DINIZ, 2012). A despeito dessas falhas, o Código Civil Brasileiro não comprometeu o instituto da sociedade limitada, que continua sendo um dos principais tipos societários do país.

Resumindo, o Brasil teve apenas duas leis federais regulando as sociedades limitadas em quase cem anos: o Decreto no 3.708 de 1919 e o Código Civil de 2002, com as diferenças preliminarmente já apontadas.

Vale ressaltar que há dois projetos de novo Código Comercial Brasileiro tramitando paralelamente, desde 2013. Qualquer um deles, se promulgado, tratará das sociedades limitadas, revogando essa parte do Código Civil. Um dos projetos está no Senado, enquanto o outro se encontra na Câmara dos Deputados (BRASIL, 2011, 2013). A menos que ocorra uma mudança drástica no cenário político brasileiro, é pouco provável que qualquer um deles seja aprovado em um futuro próximo.

Nos Estados Unidos, diversamente, durante muitas décadas, houve apenas as sociedades anônimas de um lado e as general partnerships (normalmente chamadas apenas de partnerships) do outro (KEATINGE, 1992). A primeira é personificada (incorporated business), enquanto a última é despersonificada (unincorporated business). Entre esses dois extremos, havia apenas a Limited Partnership (LP), muito menos utilizada. No entanto, a partir da década de 90, 
surgiram novos tipos societários: ${ }^{21}$ Limited Liability Partnership (LLP), Limited Liability Limited Partnership (LLLP) e a Limited Liability Company (LLC). Esta última é a que nos interessa, sendo equivalente à sociedade limitada brasileira e considerada a mais bem-sucedida entre os novos tipos societários. ${ }^{22}$

O lobby de mercado desempenhou papel fundamental na introdução desse modelo societário nos Estados Unidos. Desde os anos 60, as principais sociedades anônimas norte-americanas controlavam sociedades em outros países, valendo-se da estrutura das sociedades limitadas. No entanto, elas não podiam fazer o mesmo no mercado interno, porque a sociedade limitada não existia nos EUA. A Hamilton Brothers Oil era uma dessas companhias controladoras e decidiu persuadir os legisladores estaduais a promulgar uma lei com a criação do tipo societário semelhante nos Estados Unidos. A primeira tentativa ocorreu no estado do Alasca, em 1976, e, surpreendentemente, falhou (HAMILL, 1998). Na segunda tentativa, a Hamilton Brothers Oil foi ao Wyoming, mas dessa vez, obteve êxito, e a lei foi promulgada em 4 de março de 1977, nos exatos termos propostos pela companhia. ${ }^{23}$

Depois disso, a parte tributária se tornou crítica. Nos Estados Unidos, a distribuição de dividendos em sociedade anônima é tributada tanto da sociedade que os pagou quanto de cada acionista beneficiado (double-taxation). ${ }^{24}$ Diferentemente, os sócios de uma partnership pagam tributos federais sobre o lucro societário apenas no âmbito individual dos sócios (pass-through), e, na maioria dos casos, a tributação da partnership é mais favorável aos sócios. Inicialmente, a IRS aplicava um teste, caso a caso, para definir como a LLC deveria ser tributada, entretanto a incerteza desse método bloqueou o desenvolvimento do novo tipo societário. ${ }^{25}$ Essa situação perdurou até 1997, quando a IRS resolveu o problema ao determinar que a LLC teria, em regra, o mesmo tratamento tributário da partnership, a não ser que ela expressamente optasse por ser tratada como uma sociedade anônima, o que deveria ser firmado com a marcação de um "X" no campo específico do formulário ("check-the-box"). Com a questão tributária superada, vários estados-membros promulgaram suas próprias leis sobre LLC e o novo tipo societário deslanchou.

Para evitar problemas relacionados à diversidade de leis estaduais, o Subcomitê Especial de LLCs da American Bar Association (equivalente à OAB nos EUA) elaborou o projeto de uma lei uniforme sobre LLC, publicado em novembro de 1992. No entanto, os estados-membros já estavam com trâmites avançados para publicar leis consagrando esse novo tipo societário. Assim, muitas leis estaduais foram promulgadas antes do projeto de lei uniforme, ${ }^{26}$ consequentemente, a primeira geração de leis estaduais foi bastante diversificada em suas previsões.

Novamente, a Comissão de Legislação Uniforme (Uniform Law Commission) interviu e promulgou, em 1996, a primeira lei uniforme sobre LLC, conhecida como ULLCA. O problema foi que apenas alguns estados-membros alteraram sua legislação interna em conformidade com a ULLCA. Em nova tentativa de garantir a uniformidade entre as leis estaduais, a Comissão de Legislação Uniforme publicou, em 2006, a Lei Revisada Uniforme das Sociedades Limitadas, Revised Uniform Limited Liability Company Act (RULLCA), alterada por último em 
2013. O resultado foi que um número ainda menor de estados adotou a RULLCA. Isso se deu porque, em parte, alguns dos principais especialistas no tema apontaram vários problemas e contradições em seu texto. ${ }^{27}$

Por causa desse processo histórico, a LLC ainda é o tipo societário com menor uniformidade nos EUA, o que não significa que ela não seja importante. Certamente ela é muito importante, tanto que todos os estados-membros possuem lei sobre LLC atualmente. ${ }^{28} \mathrm{Na}$ verdade, trata-se de um dos tipos societários mais populares (senão o mais popular), tanto no Brasil quanto nos EUA, de acordo com algumas estatísticas. No Brasil, as sociedades limitadas representam aproximadamente $72 \%$ das sociedades registradas ${ }^{29}$ e compreendem tanto as grandes empresas (como holdings) quanto as médias e pequenas empresas, inclusive startups, em praticamente todos os mercados, regulados ou não. Nos Estados Unidos, as LLCs já representam mais de um terço de todas as empresas registradas (GOMTSIAN, 2015, p. 207), além de serem o tipo societário dominante entre as de menor porte (KLEIN; COFFEE; PARTNOY JUNIOR, 2010, p. 51). Esse número é extraordinário, tendo em vista que a LLC é um dos tipos societários mais recentes naquele país, e, assim como no Brasil, ela se espalha por vários setores de mercado e empresas de diferentes portes. O impacto das LLCs na economia estadunidense é tão forte que a revista The Economist cunhou um novo termo para isso: "distorporation" (GOMTSIAN, 2015, p. 208-209).

Apesar das semelhanças, também há profundas diferenças regulatórias entre os dois países. Os próximos tópicos irão destacar algumas delas.

\section{ALGUMAS DAS PRINCIPAIS DIFERENÇAS ENTRE AS LEGISLAÇÕES BRA- SILEIRA E ESTADUNIDENSE SOBRE SOCIEDADES LIMITADAS}

Como mencionado na seção "Objetivo do Artigo e Método", o propósito desta pesquisa não é cobrir todas as diferenças entre a legislação uniforme sobre LLC nos Estados Unidos e sobre sociedade limitada no Brasil. Em vez disso, o método proposto foi abordar apenas algumas das principais questões, atinentes a cinco aspectos chave desse tipo societário: a) Constituição. b) Administração e Controle. c) Direitos e Obrigações. d) Transferência de Participações Societárias. e) Dissolução Parcial e Total. O escopo, então, é propiciar ao leitor uma visão panorâmica e comparativa dos dois sistemas.

\subsection{CONSTITUIÇÃO}

O sistema brasileiro exige que os fundadores de uma sociedade limitada arquivem um documento perante o órgão de registro competente ${ }^{30}$ antes que a sociedade comece a atuar (art. 967) (BRASIL, 2002). O mesmo ocorre nos Estados Unidos, no entanto, daí em diante, há enormes diferenças (Seções 110 (a) e 201 (d)) (THE UNITED STATES OF AMERICA, 2017). 
No Brasil, por exemplo, várias das cláusulas que regulam as sociedades limitadas precisam ser publicamente registradas por meio do contrato social, por isso esse contrato deve necessariamente adotar a forma escrita. O Código Civil impõe uma extensa lista de cláusulas obrigatórias, como as que tratam de: quantidade e identificação dos sócios; nome, objeto e sede da sociedade; contribuição de cada sócio para o capital social; participação de cada sócio nos lucros e nas perdas; outros direitos e deveres dos sócios; procedimento adequado em caso de dissolução parcial ou total etc. (art. 997) (BRASIL, 2002). Além disso, os sócios podem inserir no contrato social quaisquer outras cláusulas que acharem convenientes, desde que lícitas. Como se pode perceber, as leis brasileiras impõem nivel extremo de publicidade em relação às previsões contratuais da sociedade limitada, e qualquer interessado pode requerer uma cópia deste documento ao registro público.

Em relação às cláusulas facultativas, é possível inserir previsões complementares vinculantes para um ou mais sócios, em contrato privado (não registrado), similar ao acordo de acionistas. Ele denomina-se acordo de cotistas (BULGARELLI, 1995), no entanto a extensão deste acordo é restrita pelo fato de haver várias cláusulas obrigatórias.

Os Estados Unidos adotam sistema completamente diferente, por exemplo, apenas um número mínimo de cláusulas precisa ser registrado publicamente, e todo o restante está sujeito à liberdade de contratar, sendo definido em âmbito privado pelos sócios. Sendo assim, há dois documentos que regem a LLC nos EUA, o primeiro contém as cláusulas obrigatórias e deve ser arquivado perante a Secretaria de Estado, trata-se do "Certificado de Organização" (Certificate of Organization) ou "Artigos de Organização" (Articles of Organization) (Seções 102 (1) e 201 (b)) (THE UNITED STATES OF AMERICA, 2017). Esse documento é estruturante (skeletal) e contém apenas o mínimo de informaçôes sobre a sociedade, como o nome da LLC, os seus sócios fundadores (registered agents) e os respectivos endereços. O segundo documento, que efetivamente regula o funcionamento da LLC, é o "Acordo Operacional" ("Operating Agreement"), ${ }^{31}$ que se trata de um contrato privado dos sócios, não registrado. Ele pode ter forma escrita, oral ou até ser implícito. ${ }^{32}$ Frequentemente, ocorre de os tribunais estadunidenses decidirem os casos com base nesse documento.

Outra grande diferença entre as legislações brasileira e estadunidense diz respeito à contribuição com serviços para a integralização do capital social da limitada. No Brasil, o legislador nunca permitiu esse tipo de contribuição. Além disso, o Decreto Federal no 3.708 de 1919 proibia tal ação, e o Código Civil de 2002 traz previsão semelhante. ${ }^{33}$ Portanto, os sócios devem contribuir para a formação do capital social por outros meios, como a integralização de direitos, bens, imóveis etc. Enquanto, por outro lado, os Estados Unidos permitem qualquer tipo de contribuição, inclusive serviços. ${ }^{34}$

Com relação ao número mínimo de sócios para a constituição de uma sociedade limitada, o Brasil exige pelo menos dois. ${ }^{35}$ Em outras palavras, o Brasil proíbe a sociedade limitada unipessoal, então a alternativa para o investidor individual é outra espécie de pessoa jurídica, bastante controversa, ${ }^{36}$ denominada "Empresa Individual de Responsabilidade Limitada 
(EIRELI)". No entanto, a EIRELI tem requisitos ainda mais rigorosos do que a sociedade limitada, por exemplo, via de regra, não há exigência legal de capital mínimo nas sociedades limitadas. Na EIRELI, diferentemente, era necessário capital mínimo de cerca de U\$ 28.000,00 (vinte e oito mil dólares) em 2017. ${ }^{37}$ Então, nos Estados Unidos, é perfeitamente possível constituir uma LLC unipessoal (single-member LLC). ${ }^{38}$

O último aspecto acerca da constituição de sociedade limitada aqui mencionado diz respeito à disposição que deve prevalecer em caso de conflito de regras jurídicas: (i) as leis; ou (ii) o contrato celebrado entre os sócios (contrato social ou operating agreement). No Brasil, as disposições legais normalmente são cogentes (mandatory), que prevalecem sobre as cláusulas contratuais (menor liberdade contratual, porém maior uniformidade e previsibilidade) (PRADO et al. 2011). Excepcionalmente, algumas regras legais expressamente afirmam ser subsidiárias, ao empregar expressões, como "salvo disposição contratual diversa" ou algo similar. ${ }^{39}$

Por outro lado, em alguns estados norte-americanos, como em Delaware, as leis estaduais são majoritariamente subsidiárias. ${ }^{40} \mathrm{O}$ raciocínio é justamente o oposto: a não ser que uma regra expressamente se afirme como cogente, o operating agreement pode licitamente alterar essa regra, segundo a vontade dos sócios da LLC (maior liberdade contratual, porém menor uniformidade e previsibilidade). $\mathrm{O}$ mesmo ocorre ao considerar a RULLCA como parâmetro de comparação. ${ }^{41}$

\subsection{ADMINISTRAÇÃO E CONTROLE}

Em ambos os países, a sociedade limitada pode ser administrada pelos próprios sócios (member-managed) ou também por terceiros, não sócios (manager-managed). No primeiro modelo, todos os sócios têm iguais poderes de administração (cada sócio é também administrador e pode representar a sociedade para, em nome dela, contrair direitos e obrigações perante terceiros, salvo disposição diversa no contrato social). ${ }^{42}$ Essa estrutura é semelhante à das partnerships, diferentemente, em uma sociedade limitada administrada por terceiros, apenas um específico e delimitado grupo de pessoas - composto por alguns sócios, administradores profissionais contratados ou ambos - pode representar a sociedade, a ponto de seus atos vincularem a pessoa jurídica. ${ }^{43}$ Os demais sócios ficam excluídos da administração, equivalente ao que ocorre nas sociedades anônimas, em que apenas os diretores podem representar a companhia, seguindo as ordens do conselho de administração.

Portanto, a estrutura do tipo manager-managed pode compreender três grupos de pessoas: (i) sócios que não exercem qualquer poder de gestão na sociedade; (ii) sócios que também são administradores; ou (iii) não sócios, contratados para exercer a função de administrador.

Novamente, em ambos os países, a regra é que a sociedade limitada seja member-managed, salvo disposição diversa no contrato social ou no operating agrément. ${ }^{44}$ Apesar dessas semelhanças, daqui por diante, há diferenças consideráveis entre a administração e o controle das sociedades limitadas brasileiras e das LLCs. 
No Brasil, o direito ao voto necessariamente será proporcional à participação do sócio no capital social (equity interests), ou seja, maior contribuição significa maior número de votos na sociedade. Ao tratar desse tema, o Código Civil empregou o termo "capital" 45 ao invés de "capital votante" ou algo similar, geralmente, utilizado para destacar as situações nas quais parte do capital social não possui direito ao voto, como ocorre nas sociedades anônimas com ações preferenciais. Portanto, na sociedade limitada, o Código Civil se referiu a todo o capital social, não apenas ao votante. Ademais, o artigo 1.010 prevê expressamente que todas as cotas têm direito ao voto. Sendo assim, alguém que contribuiu para a formação do capital social com US\$10.000,00 (dez mil dólares) terá, via de regra, 10 (dez) vezes mais votos do que alguém que contribuiu com US\$1.000,00 (mil dólares) porque o Código Civil impõe altos quóruns de deliberação, por exemplo, 75\%. ${ }^{46}$ Caso a sociedade limitada pudesse ter cotas sem direito de voto, seria difícil - para não dizer impossível - alcançar esses quóruns. ${ }^{47}$

Nos Estados Unidos, os sócios podem escolher se seus votos serão per capita (um ou mais votos previamente concedidos a cada sócio, independentemente de sua contribuição para o capital social) ou pro rata (direito ao voto proporcional à contribuição para o capital social)..$^{48}$ O operating agreement é o documento adequado para realizar essa definição.

Questão correlata consiste em definir se todos os sócios devem ter direito de voto nas deliberações da LLC ou se um ou mais deles podem permanentemente renunciar a esse direito. No Brasil, apesar de não estar expresso na legislação e ser controverso entre os juristas ${ }^{49}$ o Departamento de Registro Empresarial e Integração (DREI) determinou que nenhum sócio pode permanentemente renunciar ao direito de voto. ${ }^{50}$ Logo, votar nas deliberações de uma sociedade limitada brasileira é mais um dever do que apenas um direito dos sócios.

Os Estados Unidos não só aceitam cotas sem direito de voto (non-voting LLC ownership units) ${ }^{51}$ como vão além, autorizando, em alguns estados-membros, a figura da series LLC SLLC. A SLLC é uma forma adicional de limitação de responsabilidade por meio da qual os operating agreements podem criar uma ou mais classes de cotas - com administradores, patrimônio, direitos e deveres separados - dentro de uma mesma sociedade limitada (como se fossem diferentes classes de ações em uma sociedade anônima). Porém, com uma significativa diferença: apenas os ativos de cada classe podem ser atingidos para arcar com os débitos dessa classe, blindando (shielding) as demais classes e o restante do patrimônio da pessoa jurídica. ${ }^{52}$ Delaware foi o primeiro estado-membro a adotar essa modalidade, em 1996. ${ }^{53}$ A SLLC é um tema bastante controverso, tendo em vista que ainda há várias dúvidas, por exemplo, em relação aos seguintes aspectos: (i) à falência de uma ou mais classes de cotas ao invés da falência da sociedade como um todo; (ii) ao tratamento tributário de cada classe; (iii) como lidar com diferentes responsabilidades quando uma LLC sediada em determinado estado-membro atua em outros estados (foreign company), nos quais não há autorização legislativa para a constituição de SLLC. ${ }^{54}$ Assim, para evitar esses problemas, a RULLCA simplesmente não permite SLLCs. 
Outro tópico relevante é o quórum de deliberação. O Código Civil Brasileiro impõe quóruns deliberativos obrigatórios que não podem ser alterados pelo contrato social. Há quóruns obrigatórios, por exemplo, para a eleição e a destituição de administradores. ${ }^{55}$ Nas sociedades limitadas administradas pelos próprios sócios, o quórum para esse tipo de deliberação é de (i) 2/3 (dois terços) do capital social, caso este esteja totalmente integralizado ou (ii) unanimidade se o capital social ainda não estiver integralizado. ${ }^{56}$ Como já mencionado, os quóruns no Código Civil Brasileiro geralmente são elevados e, por isso, muito criticados pelos juristas.

Nos Estados Unidos, a RULLCA prevê uma regra geral e algumas exceções. A regra é que, no curso normal dos negócios, os sócios podem tomar decisões pela maioria dos votos, ${ }^{57}$ por exemplo, para eleger ou destituir administradores. Essa regra, é subsidiária, de forma que o operating agreement pode alterá-la de acordo com as preferências de cada LLC. Contudo, em alguns casos, a RULLCA exige o consentimento unânime dos sócios, como nas decisões fora do curso normal dos negócios ou na pretensão alterar o próprio acordo operacional. ${ }^{58}$ Essas previsões excepcionais claramente acarretam o bloqueio das deliberações (lock-in effect), basta imaginar a situação na qual 99\% dos votos convergem, mas a decisão ainda assim não é unânime. Tal situação chega a ser até mais problemática do que os elevados quóruns da legislação brasileira.

\subsection{DIREITOS E OBRIGAÇÕES}

Em relação aos direitos e às obrigações, a regra padrão no Brasil determina que, salvo disposição diversa no contrato social, cada sócio participa nos lucros e nas perdas na mesma proporção de sua participação no capital social, ${ }^{59}$ por exemplo, $10 \%$ das cotas sociais atribuem ao seu titular $10 \%$ de todos os lucros e perdas. No entanto, o contrato social pode prever distribuição diversa, como na hipótese de o sócio titular de 30\% das cotas receber 20\% dos lucros e $10 \%$ dos prejuízos. O limite imposto à liberdade de contratar é o artigo do Código Civil que impõe que todos os sócios da sociedade limitada devem participar da distribuição de lucros e perdas. ${ }^{60}$ Sendo assim, é possível estipular contratualmente que um sócio terá direito a 99\% dos lucros da sociedade ou apenas 1\% das perdas, independentemente de sua participação no capital social. No entanto, é ilegal conceder a qualquer sócio 100\% ou 0\%.

Com base nisso, diversas sociedades, incluindo alguns escritórios de advocacia (GONÇALVES NETO, 2006, p. 58-61), admitem profissionais em início de carreira como sócios ao invés de contratá-los como empregados, principalmente, porque a legislação trabalhista brasileira impõe custos exacerbados para contratar, manter e demitir funcionários. Assim, admitir sócios ao invés de contratar empregados é um meio lícito de evitar esses custos. Por óbvio, essas pessoas devem ser tratadas como verdadeiros sócios, com as prerrogativas atinentes a tal condição, caso contrário, a relação será considerada fraudulenta pela legislação trabalhista. ${ }^{61}$

Nos Estados Unidos, essa questão é, em parte, semelhante e, em parte, distinta do que se passa no Brasil. Semelhante porque a regra padrão da RULLCA é no sentido de que a 
participação nos lucros e nas perdas é proporcional à quantidade de cotas de cada sócio. ${ }^{62}$ A diferença é que a RULLCA não pró́be excluir qualquer sócio da participação nos lucros e nas perdas. Consequentemente, nos EUA, essa questão é puramente contratual, e os limites impostos pela RULLCA relacionam-se mais à proteção de terceiros e credores que contratam com a sociedade do que com os interesses privados dos sócios. ${ }^{63}$

\subsection{TRANSFERÊNCIA DE PARTICIPAÇÕES SOCIETÁRIAS}

Tanto no Brasil quanto nos Estados Unidos, a participação em uma sociedade limitada (LLC ownership unit) confere ao sócio direitos de conteúdo econômico (financial rights - como a participação nos lucros) e de administração (management rights - representar a sociedade perante terceiros, assinar contratos ou ajuizar demandas em nome da pessoa jurídica, além de decidir como empregar seus ativos). Além disso, em ambos os sistemas jurídicos, os sócios podem transferir esses direitos conjunta ou separadamente. ${ }^{64}$ É possível, por exemplo, conferir a terceiro apenas os direitos econômicos de uma ou mais cotas, enquanto o cotista mantém os direitos de voto e de participar da administração da sociedade. A despeito dessa semelhança básica, existem diferenças significativas na maneira como a legislação dos dois países trata do tema.

No Brasil, a regra geral é a de que o cotista pode transferir livremente sua participação societária a qualquer pessoa, englobando tanto os direitos econômicos quanto políticos (de voto, por exemplo), entretanto o procedimento varia conforme o adquirente seja outro sócio ou um terceiro não sócio. O Código Civil determina que a transferência de cotas entre sócios é livre e o cedente não precisa notificar os demais sócios a respeito de sua intenção, porque eles não têm direito de preferência para aquisição das cotas. Por outro lado, a transferência a terceiros também é livre, mas o cedente deve notificar previamente os demais sócios, porque eles têm o direito de impedir o ingresso de sujeitos indesejados, se houver justa causa e se isso for decidido por mais de $25 \%$ do capital social. ${ }^{65}$

Ademais, em uma sociedade limitada administrada pelos próprios sócios (member-managed), ainda que o contrato social preveja que todos eles são também administradores, essa cláusula se aplica apenas aos fundadores. Em outras palavras, quem ingressar posteriormente como sócio não se tornará automaticamente administrador, mas sim adquirirá apenas os direitos econômicos e políticos que decorrem das cotas. Ademais, para se tornar administrador, deverá ser eleito pelos sócios, de acordo com o respectivo quórum. ${ }^{66}$

Em suma, a regra geral no Brasil é um incentivo à livre circulação de cotas entre os sócios, sem, contudo, negligenciar o direito dos demais sócios de impedir o ingresso de terceiros. Além disso, o sócio ingressante adquire os direitos econômicos e políticos, mas não se torna administrador, a não ser que seja expressamente nomeado para a função (GONÇALVES NETO, 2012, p. 361-362).

Nos Estados Unidos, apenas os direitos econômicos são livremente transferiveis sem necessidade de consentimento prévio. Para a transferência de direitos de administração, a RULLCA exige o consentimento de todos os demais sócios, independentemente de o adquirente ser um 
terceiro ou alguém que já é sócio, ${ }^{67}$ regra semelhante à das partnerships. ${ }^{68}$ Por um lado, ela preserva a estrutura de controle que existia anteriormente ao negócio jurídico (tal como sucede no Brasil). Por outro lado, a exigência de consentimento unânime cria um lock-in.

Evidentemente, ambos os países permitem que os sócios afastem a incidência da regra geral por meio do contrato, seja para permitir a livre transferência de participações societárias, seja para restringi-la ainda mais, por exemplo, no Brasil, quando o contrato social prevê direito de preferência aos sócios remanescentes em caso de transferência de cotas a terceiros e, nos EUA, ao permitir que a transferência dos direitos políticos se dê com quórum menor, o de maioria simples. Do ponto de vista jurídico, o aspecto central é que não importa se contratada para restringir ou para facilitar a transferência de participações societárias, é extremamente recomendável que os sócios consignem essa cláusula por escrito, antes do possível surgimento de conflitos. ${ }^{69}$

Por último, outra diferença significativa entre as legislações brasileira e estadunidense diz respeito à emissão de valores mobiliários por sociedades limitadas. No Brasil, desde sua inserção no ordenamento jurídico, em 1919, esse tipo societário nunca foi autorizado a realizar oferta pública de cotas, pelo fato de que as cotas não são consideradas valor mobiliário, consequentemente, não há mercado público de ampla negociação para elas, apesar de que, nos últimos anos, a $\mathrm{CVM}^{70}$ vem gradativamente decidindo que as sociedades limitadas podem realizar oferta pública de algumas espécies de valor mobiliário, como notas comerciais (commercial papers), cédulas de crédito bancário ${ }^{71}$ e notas promissórias, ${ }^{72}$ bem como receber aportes financeiros provenientes de Fundos de Investimentos em Participações (FIPs). ${ }^{73}$ A tendência é o crescimento da relação de valores mobiliários que podem ser emitidos por sociedades limitadas ${ }^{74}$ contudo, atualmente, as cotas não integram essa relação.

Nos Estados Unidos, as cotas da LLC também não podem ser comercializadas como valor mobiliário, no entanto algumas estratégias lícitas permitem driblar essa regra. Esse fato ocorre principalmente em Delaware, em virtude do elevado grau de liberdade contratual admitido pela legislação societária local, Delaware Limited Liability Company Act (DLLCA), por isso 20 (vinte) LLCs listadas publicamente foram constituídas nesse estado, até o ano de 2013. ${ }^{75}$ Nesse contexto, a jurisprudência vem discutindo se as cotas da LLC constituem valor mobiliário, e a principal linha argumentativa aplica um teste criado para as sociedades anônimas, conhecido como "Howey Test", a fim de definir se a cota social pode ser tratada como contrato de investimento e, por conseguinte, como valor mobiliário. Como os sócios da LLC somente saberão se as suas cotas são ou não valor mobiliário a partir de uma análise casuística, geralmente, realizada no curso de um processo judicial, os problemas desse método são a incerteza e a imprevisibilidade (GIRNYS, 2011, 2012). No final das contas, os tribunais frequentemente proferem decisões diferentes para as sociedades com estrutura semelhante. ${ }^{76}$

\subsection{DISSOLUÇÃO PARCIAL E TOTAL}

Nesse tema, há distinções conceituais importantes. Isso se dá pelo fato de a liquidação antecipada do ativo societário em relação a algum cotista (withdrawal of a member capital con- 
tribution) se diferenciar da saída de sócio da sociedade limitada (withdrawal from the LLC). A primeira ocorre quando o sócio recebe de volta parte ou todo o valor pecuniário a que teria direito em caso de liquidação antecipada do ativo societário, fazendo que este direito seja reduzido (ou mesmo extinto) proporcionalmente ao valor recebido, porém o beneficiário permanece sendo sócio da pessoa jurídica, de forma que poderá, por exemplo, participar dos lucros e das perdas, atuar como administrador e votar nas deliberações societárias. Como qualquer direito ao crédito, a participação do sócio no ativo da LLC pode ser resgatada ou transferida pelo titular, segundo a sua vontade. Diversamente, a saída do sócio (withdrawal from the LLC) corresponde à negociação de buyout, por meio da qual o sócio retirante recebe de volta o valor correspondente a sua participação societária no momento da retirada e, consequentemente, deixa de ser sócio (PARENTONI; LIMA, 2016, p. 314).

Outra diferença basilar é entre dissolução parcial (dissociation) e dissolução total (dissolution). A dissolução total ocorre quando todos os sócios deixam a sociedade, a qual deve ser então liquidada e, na sequência, extinta, ou seja, a pessoa jurídica deixa de existir. Por outro lado, se apenas um ou mais sócios deixam a sociedade (independentemente de o fazerem por vontade própria ou terem sido excluídos), a sociedade permanece ativa e, sendo conduzida pelos sócios remanescentes, ocorre a dissolução parcial (BABRI FILHO, 2004; FONSECA, 2012).

No Brasil, em se tratando de sociedade limitada constituída por prazo indeterminado (LLC at will) - o que significa a pessoa jurídica sem prazo final de duração pré-definido no contrato social ou que não se enquadre como sociedade de propósito específico - qualquer sócio pode desvincular-se a qualquer momento. Basta comunicar sua intenção à sociedade com pelo menos 60 (sessenta) dias de antecedência. ${ }^{77}$ Em relação a eventos futuros, seus deveres para com a sociedade e os credores terminam na data em que a sociedade recebe a mencionada comunicação, independentemente de os valores devidos ao sócio retirante serem pagos à vista ou parceladamente. ${ }^{78}$

Excepcionalmente, se um ou mais sócios tiverem feito substanciais investimentos na sociedade, ${ }^{79}$ confiando que os demais sócios permaneceriam vinculados à pessoa jurídica até que ela tivesse chance real de recuperar tais investimentos, os investidores podem ajuizar uma demanda para forçar os demais sócios a permanecerem na sociedade, por um periodo razoável. ${ }^{80}$

Nos Estados Unidos, após a reforma tributária “check-the-box”, várias leis societárias estaduais foram modificadas para restringir o direito de retirada, a não ser que o contrário tenha sido contratualmente estipulado pelos sócios. Contudo, a RULLCA seguiu na contramão dessa deliberação, ao determinar que "a pessoa tem o direito de se retirar da sociedade a qualquer tempo, com ou sem justa causa." (THE UNITED STATES OF AMERICA, 2017, online). ${ }^{81}$ Os direitos e os deveres do sócio retirante terminam na data da dissolução parcial, com relação aos eventos que vierem a ocorrer a partir dessa data. ${ }^{82}$ Nesse ponto, as regras brasileira e estadunidense são semelhantes.

Com relação à sociedade limitada constituida por prazo determinado (LLC for a definite term of duration), no Brasil, a regra é que nenhum sócio pode se retirar da sociedade antes de 
decorrido o prazo estipulado em contrato, salvo com autorização expressa dos demais. ${ }^{83}$ Caso esse consentimento unânime não possa ser alcançado, a alternativa é ajuizar uma demanda na qual o ônus da prova quanto à justa causa recairá sobre o cotista que pretende se retirar da sociedade. Nesse caso, o vínculo societário do retirante será extinto apenas com o trânsito em julgado da sentença que decidir a seu favor. ${ }^{84}$

Nos Estados Unidos, a RULLCA dispõe que qualquer sócio tem o direito de se retirar da sociedade, antes mesmo de decorrido o prazo de duração, entretanto, se o operating agreement dispuser em sentido contrário, ainda que isso não seja suficiente para proibir a retirada, o sócio que optar por sair da sociedade ficará civilmente responsável por indenizar os danos que sua conduta possa causar não apenas à pessoa jurídica como também aos sócios remanescentes. ${ }^{85}$

A forma de pagamento e o prazo para buyout na dissolução parcial também são diferentes no Brasil e nos EUA. No Brasil, os haveres devidos ao sócio que se retira devem ser pagos à vista e em dinheiro, no prazo máximo de 90 (noventa) dias, salvo disposição diversa no contrato social. ${ }^{86}$ Nos EUA, a RULLCA não contém regra semelhante, o que faz que a definição possa ser feita no operating agreement ou por deliberação dos sócios, caso o referido contrato também seja silente.

A inovação do sistema brasileiro são os requisitos e os procedimentos obrigatórios impostos pelo Código Civil para a exclusão extrajudicial de sócios da sociedade limitada. ${ }^{87}$ Portanto, esse procedimento somente será aplicável se: (i) o contrato social contiver cláusula autorizando-o; (ii) for provada justa causa; (iii) a deliberação for tomada em assembleia ou reunião de sócios especialmente convocada para essa finalidade; (iv) for assegurado direito de defesa ao sócio que se pretende excluir, durante a mencionada deliberação; e (v) apenas sócios minoritários puderem ser excluídos dessa maneira. A RULLCA, por outro lado, deixa a questão integralmente a critério da decisão privada dos sócios, com muito maior liberdade contratual, ao dispor que "a pessoa é excluida como sócia nos termos do acordo de operação." (THE UNITED STATES OF AMERICA, 2017, online) ${ }^{88}$

\section{CONCLUSÃO}

A sociedade limitada é um dos tipos societários mais importantes tanto no Brasil quanto nos Estados Unidos, contudo esses países possuem tradição jurídica muito diferente, consequentemente, suas legislações regulam o tema de maneiras distintas e, algumas vezes, até contraditórias. Esta pesquisa buscou destacar algumas dessas diferenças, com relação aos seguintes aspectos da sociedade limitada (LLC): a) Constituição; b) Administração e Controle; c) Direitos e Obrigações; d) Transferência de Participações Societárias; e) Dissolução Parcial e Total.

Ao final, chegou-se à conclusão de que, apesar de o Brasil possuir maior tradição em matéria de sociedades limitadas, por tê-las inserido no ordenamento jurídico há mais de cem anos, os Estados Unidos alcançaram um destacável desenvolvimento nas últimas décadas, inclusive quando supera a legislação brasileira em temas muito importantes, como as for- 
mas de se integralizar o capital social, o tratamento do direito ao voto e o instituto da series LLC - SLLC. Ao mesmo tempo, o Brasil continua à frente em temas, como a transferência de participações societárias entre os próprios sócios, compreendendo tanto os direitos econômicos quanto os políticos.

A análise de legislação comparada desenvolvida nesta pesquisa pode ser útil para melhor compreender a lógica que guia cada sistema jurídico, identificando os prós e os contras de suas respectivas previsões sobre um mesmo assunto. Portanto, constitui o primeiro passo para todo aquele que deseja compreender tais sistemas em maior profundidade. Além disso, este estudo se mostra importante também porque pode ser relevante para governos e outros agentes reguladores, quando estiverem reavaliando ou alterando suas regras.

\title{
LIMITED LIABILITY COMPANY - LLC: SOME MAJOR DIFFERENCES BETWEEN BRAZIL AND THE US LEGISLATION
}

\begin{abstract}
This article draws a parallel between limited liability company - LLC in Brazil and the US, from a regulatory perspective, based just on a study of compared legislation: The Civil Code, in Brazil, and the Revised Uniform Limited Liability Company Act - RULLCA, in the US. The scope is to highlight some major differences between these legal systems when dealing with the same issue. In the end, I expect that this study helps to identify pros and cons of the uniform regulatory framework of LLCs in both countries, which could be useful when reevaluating or amending their laws.
\end{abstract}

Keywords: Limited society (LTDA). Limited Liability Company (LLC). Comparative Legislation.

\section{SOCIEDAD DE RESPONSABILIDAD LIMITADA - LLC: ALGUNAS DE LAS PRINCIPALES DIFERENCIAS ENTRE LA LEGISLACIÓN BRASILEÑA Y LA ESTADOUNIDENSE}

\section{RESUMEN}

Este artículo establece un paralelo entre la sociedad de responsabilidad limitada en Brasil y en los Estados Unidos de América, desde la perspectiva del regulador, basándose en el análisis comparativo de legislaciones: el Código Civil de Brasil y la última versión de la Ley Uniforme de las Sociedades de Responsabilidad Limitada (Revised Uniform Limited Liability Company Act - RULLCA) en los Estados Unidos de América. El objetivo es destacar algunas de las principales diferencias entre estos dos sistemas jurídicos cuando tratan el mismo tema. 
Al final, espérase que este artículo ayude a identificar las ventajas y las desventajas de la regulación de sociedades de responsabilidad limitada en los dos países, lo que podría ser muy útil para una reevaluación y modificación de sus leyes.

Palabras clave: Sociedad Empresaria Limitada. LLC. Legislación Comparativa.

1 Este texto constitui a tradução de pesquisa escrita originariamente em inglês, fruto do acordo entre a Universidade do Texas em Austin (Teresa Lozano Long Institute of Latin American Studies - LLILAS) e a Fundação de Amparo à Pesquisa de Minas Gerais (FAPEMIG), instituições que financiaram o período de estudos do autor em Austin/EUA, em 2017. Algumas adaptações foram feitas no texto, tendo em vista a diferença estrutural entre os idiomas, porém optou-se por manter a tradução, tanto quanto possível, fiel à versão original. Peço desculpas antecipadamente por eventuais erros de tradução que tenham passado despercebidos.

2 'As chamadas 'leis uniformes' não são, a rigor, lei em sentido estrito. Nem sequer ato infralegal. Constituem, na verdade, propostas elaboradas por grupos de juristas, para servirem de inspiração aos diversos Estados-membros, no tratamento legislativo de determinado tema. Espera-se que os Estados-membros, ao elaborarem sua legislação interna, incorporem as disposições da lei uniforme. Busca-se, com isto, harmonizar as legislações estaduais, reduzindo custos de transação." (PARENTONI; GONTIJO, 2016, p. 245).

3 "Onde as pessoas se comprometem em um negócio, entretanto, elas são sócias se dividirem os lucros e o controle. Esta é uma muito breve, muito rudimentar, imprecisa regra-de-ouro para definir partnerships." (KLEIN; COFFEE; PARTNOY JUNIOR, 2010, p. 63).

Tradução livre de: "Where people are engaged in a business, however, they are partners if they share in profits and control. That is the very brief, very rough, imprecise rule-of-thumb definition of partnerships."

4 "Cada estado-membro [dos EUA], por meio de sua constituição estadual e legislação interna, criou seu próprio sistema normativo, e a falta de uniformidade entre os estados-membros torna impossível descrever detalhadamente um modelo que se encaixe em todos eles." Tradução livre de: "Each state by constitution and statute has established its own system, and the lack of uniformity from state to state makes it impossible to give a detailed description to fit all states." (FARNSWORTH, 2010, p. 44).

5 Obviamente, harmonizar não significa criar regras idênticas. Apenas regras que sejam compatíveis, mesmo que possuam redações e significados distintos. Ver: (HANSMANN; KRAAKMAN, 2000; GILSON, 2000).

6 Destacando algumas das falhas no texto original da RULLCA (RIBSTEIN, 2008).

7 Para um melhor entendimento de quão difícil é desenvolver um estudo comparativo sobre sociedades limitadas na esfera estadual dos EUA e o quão importante é observar as leis uniformes, ver: Goforht (2016). Sugerindo a adoção imediata de leis uniformes sobre sociedades limitadas em Nova Iorque: "O poder legislativo de Nova Iorque deveria alterar a legislação estadual para esclarecer as inúmeras incertezas ou simplesmente adotar a RULLCA, que representa um estudo mais cuidadoso dos problemas que surgem no contexto das sociedades limitadas." (MILLER, 2015, p. 409). Tradução livre de: "The New York legislature should either amend the statute to clarify the numerous uncertainties or simply adopt the Revised Uniform Limited Liability Company Act, which represents a more careful study of the issues that arise in the LLC context."

8 (COELHO; BRANCO, 2008, p. 817-818). Não é de surpreender, por exemplo, que vários estados federados estejam quase falidos, uma vez que não conseguem pagar as dívidas à União. Em dezembro de 2016, o Congresso Nacional promulgou uma lei que melhorava as condições de pagamento dos estados. ("renegociação das dividas com a União").

9 CF/88, Artigo 22, I (BRASIL, 1988).

10 Para prós e contras dessa opção, ver: Parentoni e Gontijo (2016).

11 Há algumas outras exceções, por exemplo, pessoas jurídicas constituídas em países membros do MERCOSUL, uma vez que alguns pactos de financiamento do MERCOSUL lhes facultam sistemas menos complexos para atuação. 
12 Contudo, perceba que as leis federais possuem um papel importante no sistema. Especialmente em tempos de crises e de escândalos, como o caso Enron. Por exemplo, apenas leis federais podem versar sobre valores mobiliários, falência e outros temas. "Os Estados Unidos possuem dois sistemas de direito empresarial paralelos, que às vezes interagem. Um é estadual e o outro - incompleto, mas poderoso - é federal.” Tradução livre de: "United States has two parallel, at times interacting, systems of corporate law. One is state-made and one incomplete but powerful - is federal." (ROE, 2009, p. 3).

13 Geralmente, essa autoridade é a Secretaria de Estado (Secretary of State).

14 Vale destacar que o procedimento estadunidense é mais complexo do que o sistema brasileiro, em que basta o simples registro de filial da sociedade na Junta Comercial de outro estado-membro.

15 Para uma visão detalhada dessa distinção e de seus critérios, ver: Parentoni (2006). As raízes desta distinção vêm do Código Civil Italiano de 1942. Sobre esse assunto no direito italiano, ver: Angelici e Ferri (2006) e Auletta (2003).

16 BREWER (2013, p. 329). "A razão de ser das sociedades limitadas de baixo lucro (L3C) é o fomento dos investimentos relacionados a programas (PRIs) feitos por fundações privadas. PRIs são tipos especiais de investimentos que podem ser tanto filantrópicos quanto econômicos.» Tradução livre de: "The raison d'être for the low-profit limited liability company ("L3C") is to encourage program-related investments ("PRIs") by private foundations. PRIs are special types of investments that can be both charitable and profitable." Para a evolução histórica desse tema, ver: Wilson (2015).

17 Veja: Artigos 1052 and 1060 (BRASIL, 2002) e Seção 304 (a). (THE UNITED STATES OF AMERICA, 2017).

18 Tradução livre de: "The limited liability company ('LLC') is a noncorporate business structure that provides its owners, known as 'members', with a number of benefits: (1) limited liability for the obligations of the venture, even if a member participates in the control of the business; (2) pass-through tax treatment; and (3) tremendous freedom to contractually arrange the internal operations of the venture." (HAMILTON; MACEY; MOLL, 2014, p. 1199).

19 "[...] há um crescente entendimento de que a liberdade contratual deveria ser restringida, pelo menos em relação às entidades de Delaware, e de que restringir tal liberdade com segurança jurídica é uma tarefa árdua quando se trata de um modelo totalmente contratual.” Tradução livre de: "[...], there is a growing sense that contractual freedom should be curtailed, at least in diversely-held Delaware alternative entities, and that predictable constraints on contractual freedom are difficult to achieve under a purely contractual model." (MILLER; ANTONUCCI, 2016, p. 149). Ver também: Horton (2016).

20 Para um breve histórico do desenvolvimento das sociedades limitadas, ver: Lobo (2004, p. 47-50).

21 Larry Ribstein chamou esse fenômeno de "The Rise of the Uncorporation": (RIBSTEIN, 2010). Ver também: Hansmann, Kraakman e Squire (2005).

22 Atualmente, alguns autores sugerem a racionalização do sistema, com a extinção dos modelos menos utilizados. Por exemplo: Franklin (2016).

23 "Nada, nem mesmo uma vírgula na proposta de lei sobre sociedades limitadas sugerida pela Hamilton Brothers foi modificada pelo Legislativo de Wyoming. Prontamente assinada pelo Governador Herschler, a lei entrou em vigor em 30 de junho de 1977." Tradução livre de: "Nothing, not even a comma, in the proposed LLC legislation drafted by Hamilton Brothers was changed by the Wyoming Legislature. Promptly signed by Governor Herschler, the act became effective June 30, 1977." (BAGLEY; WHYNOTT, 1994, p.).

24 Há exceções, como a "S corporation", no entanto essas exceções vêm acompanhadas de inúmeras restrições.

$25 \mathrm{O}$ mesmo não ocorreu no Brasil, pois as sociedades limitadas e anônimas possuem regimes tributários muito semelhantes.

26 Tratando da rápida adoção das sociedades limitadas pelos estados (RIBSTEIN, 1998).

27 Por exemplo: Ribstein (2008).

28 O Havaí foi o último a promulgar, em 1997. Ver: The United States of America (2015). 
29 Dados de 2012. Dados mais recentes não foram encontrados (INSTITUTO BRASILEIRO DE PLANEJAMENTO E TRIBUTAÇÃO, 2012, p. 9).

30 As Juntas Comerciais para as Sociedades Empresárias e o Cartório de Registro Civil das Pessoas Jurídicas, no caso das Sociedade Simples.

31 Seções 105 a 107. (THE UNITED STATES OF AMERICA, 2017). Discutindo se o Acordo de Operação possui natureza contratual e vinculativa: Heminway (2015).

32 Seção 102 (13). (THE UNITED STATES OF AMERICA, 2017). Acordos orais são problemáticos, principalmente quando da admissão de novos sócios. A melhor opção para os sócios geralmente é elaborar um documento escrito e colher assinaturas dos demais sócios.

33 Artigo 1055, § 2. (BRASIL, 2002).

34 Seção 402. (THE UNITED STATES OF AMERICA, 2017).

35 Perceba que os artigos 1055 e 1059 do Código Civil (BRASIL, 2002) se referem aos sócios no plural, o que significa dois ou mais, enquanto o artigo 1033, IV, permite que a sociedade limitada tenha apenas um sócio em caráter excepcional, por um prazo máximo de 180 (cento e oitenta) dias. Após decorrer esse prazo, o sócio remanescente deve recompor a pluralidade de sócios, dissolver a sociedade ou convertê-la em EIRELI.

36 Questionando a eficiência da EIRELI: Rodrigues, Ferrer e Simões (2016).

37 Artigo 980-A, caput (BRASIL, 2002).

38 Seções 201 (a) e (d). (THE UNITED STATES OF AMERICA, 2017).

39 Ver, por exemplo, os artigos 1013, caput, e 1063, § 1º, do Código Civil (BRASIL, 2002).

40 Ver: (MILLER; ANTONUCCI, 2016; HORTON, 2016).

41 Na RULLCA, normas obrigatórias excepcionais são, por exemplo, as que dizem respeito à dispensa de obrigações fiduciárias e operações de fusão e aquisição. Ver: The United States of America (2017). Seções 201 105, (c) (5), (13) e (14).

42 Artigo 1060. (BRASIL, 2002). Seções 102, (12) e 407, (b), (2). (THE UNITED STATES OF AMERICA, 2017). 43 Artigo 1060 (BRASIL, 2002). Seções 102, (10) e 407, (c), (1). (THE UNITED STATES OF AMERICA, 2017). 44 Artigo 1060 (BRASIL, 2002). Seções 407, (a) e (b), (1). (THE UNITED STATES OF AMERICA, 2017). "Na maioria das legislações estaduais, na ausência de previsão contratual ou acordo em sentido diverso, a administração da sociedade limitada será conferida aos sócios que, neste aspecto, se assemelham aos sócios de uma partnership e que não apenas participam da tomada de decisão como também têm o poder de representar a sociedade." Tradução live de "Under most statutes, in the absence of a provision or agreement to the contrary, management of the LLC is vested in the members, who are like general partners in this respect, and who not only participate in decision-making but also may have the power to bind the company." (KLEIN; COFFEE; PARTNOY JUNIOR, 2010, p. 104).

45 Por exemplo, artigos 1055 e 1057 (BRASIL, 2002).

46 Artigo 1076, I. (BRASIL, 2002).

47 Aprofundamento do tema das quotas sem direito ao voto no Brasil: Parentoni e Miranda (2016).

48 Seções 407, (c), (1). (THE UNITED STATES OF AMERICA, 2017). "As regras padrão sobre voto no âmbito da sociedade limitada são diferentes entre as leis estaduais. Cerca de metade das leis sobre LLC atribuem aos sócios direito de voto per capita (um voto por sócio), enquanto que a outra metade adota como regra o voto pro rata (proporcional à contribuição, financeira ou não, feita à sociedade)." Tradução livre de: "The default rules for voting in an LLC differ among the statutes. About half of the LLC statutes default to members voting on a per capta basis (one vote per member), while the other half default to members voting on a pro rata basis (by financial or other contribution to the firm)." (HAMILTON; MACEY; MOLL, 2014, p. 1208).

49 Ver, novamente: Parentoni e Miranda (2016).

50 Para ser mais exato, o DREI determinou que uma sociedade limitada pode ter quotas preferenciais, com direitos e obrigações diferentes das ordinárias, desde maio de 2017, mas que elas não podem prever restrições ao direito de voto. Item 1.4, II, (b). (BRASIL, 2017). 
51 Essa definição compete ao acordo de operação, nos termos da RULLCA. Este livro clássico trata de sociedades anônimas, mas a argumentação do autor também cabe para limitadas. "A maioria dos estados-membros permite que as sociedades estabeleçam praticamente quaisquer práticas de voto que queiram. Por exemplo, Delaware permite que as sociedades atribuam às cotas qualquer número de votos (inclusive nenhum) e concedam votos a credores além (ou ao invés de) concedê-los aos acionistas. Os votos podem ser cumulativos ou não, de acordo com o que a sociedade optar." Tradução livre de: "Most states allow firms to establish almost any voting practices they please. For example, Delaware permits firms to give shares any number of votes (including none) and give votes to bondholders in addition to (or instead of) shareholders. The votes may cumulate or not, at the option of the firm." (EASTERBROOK; FISCHEL, 1991, p. 63).

52 "A series LLC é a mais recente e de longe mais sofisticada entidade negocial já criada. O conceito é o de que uma única sociedade possa ser constituída num estado-membro, mas classes ou 'células' separadas possam ser criadas dentro da LLC. [...] A series LLC é, essencialmente, uma única organização central que tem a prerrogativa de fracionar seus ativos e responsabilidades entre várias sub-LLCs ou séries. Cada sub-LLC pode ter diferentes ativos, estruturas econômicas, sócios e administradores. Os lucros, prejuízos e responsabilidades de cada classe são legalmente separados das demais classes, criando assim uma barreira entre elas. Ademais, ela elimina o ônus administrativo e as despesas para a constituição de múltiplas LLCs. A estrutura é muito semelhante à de uma holding imprópria e suas controladas, apenas sem ter os mesmos gastos, formalidades e pesada tributação." Tradução livre de "A series LLC is the latest and by far most sophisticated form of business entity created. The concept is that a single entity may be formed in a state, but separate series or 'cells' may be internally created within the LLC. [...] The series LLC is essentially a single umbrella entity that has the ability to partition its assets and liabilities among various sub-LLCs or series. Each sub-LLC may have different assets, economic structures, members, and managers. The profits, losses, and liabilities of each series are legally separate from the other series, thereby creating a firewall between each series. In addition, it eliminates the administrative burden and expense of forming multiple LLCs. The structure is very similar to a parent corporation with subsidiaries only without the expense, formalities, and heavy taxation." (THE UNITED STATES OF AMERICA, 2015, online).

$53 \S 18-215$. (ESTADOS UNIDOS DA AMÉRICA, 2017).

54 Especialmente ao considerarmos a Seção 901, (b) da RULLCA.

55 Artigo 1071, II e III c/c artigo 1076, II. (BRASIL, 2002).

56 Artigo 1061. (BRASIL, 2002).

57 Seção 407, (3) e (c), (1). (THE UNITED STATES OF AMERICA, 2017).

58 Seção 407, (4). (THE UNITED STATES OF AMERICA, 2017).

59 Artigo 1007. (BRASIL, 2002).

60 Artigo 1008. (BRASIL, 2002).

61 Artigo 9. (BRASIL, 1943).

62 Seção 404. (THE UNITED STATES OF AMERICA, 2017).

63 Seções 405 e 406. (THE UNITED STATES OF AMERICA, 2017).

64 Artigo 286. (BRASIL, 2002). Seções 401, (d), (1); 501; 502, (a), (2) e (3) (g). (THE UNITED STATES OF AMERICA, 2017).

65 Artigo 1057 (BRASIL, 2002).

66 Artigo, parágrafo único. (BRASIL, 2002).

67 Seção 401, (c), (3). (THE UNITED STATES OF AMERICA, 2017).

68 "Em relação à transferência de participações societárias, os sócios da sociedade limitada podem transferir ou conceder seus direitos econômicos na sociedade, mas na ausência de consentimento unânime entre os sócios ou previsão contratual ou acordo em sentido contrário, não podem transferir seus direitos políticos (ou seja, seu direito de voto)." Tradução livre de: "As for transferability, member of LLCs mays transfer, or assign, their financial interest in the LLC, but, in the absence of unanimous consent of the other members or a provision or an agreement to the contrary, not their right to participate in management (that is, their voting rights)." (KLEIN; COFFEE; PARTNOY JUNIOR, 2010, p. 104). 
69 Tratando da importância das previsões contratuais que abordem a transferência de participações societárias (GOMTSIAN, 2016).

70 A agência federal brasileira que regula o mercado de valores mobiliários, equivalente à SEC nos EUA.

71 Artigo 33. (BRASIL, 2009).

72 Artigo $2^{\circ}$. (BRASIL, 2015a).

73 Artigos 15 e 16. (BRASIL, 2016). Para mais detalhes, ver: Parentoni e Féres (2016).

74 Atualmente, a maior discussão gira em torno da emissão de debêntures pela sociedade limitada. Ver: Crisóstomo (2011). Seguindo a mesma linha de raciocínio: Amaral (2014).

75 Dados fornecidos por: Gomtsian (2015).

76 Para uma lista de decisões contraditórias sobre o assunto, ver: Girnys $(2011,2012)$.

77 Artigo 1029. (BRASIL, 2002).Artigoemais s significa o por maa regra nlegisladores, ao reavaliarem ou alterarem suas leis. pelos demais s significa o por ma

78 Artigo 605, II. (BRASIL, 2015b).

79 Artigoemais s significa o por maa regra nlegisladores, ao reavaliarem ou alterarem suas leis. pelos demais s significa o por ma Por exemplo, investimentos muito específicos e irrecuperáveis (sunk costs).

80 Artigo 473, parágrafo único. (BRASIL, 2002).

81 Seção 601, (a). Tradução livre de: "a person has the power to dissociate as a member at any time, rightfully or wrongfully.” (THE UNITED STATES OF AMERICA, 2017, online).

82 Seção 603, (2) de (3), (b). (THE UNITED STATES OF AMERICA, 2017).

83 Artigo 1.029. (BRASIL, 2002).

84 Assim dispõe literalmente o CPC/2015. Artigo 605, IV. (BRASIL, 2015b).

85 Seção 601, (a), (b), (I) e (c). (THE UNITED STATES OF AMERICA, 2017).

86 Artigo 1031, parágrafo segundo. (BRASIL, 2002).

87 Artigo 1085. (BRASIL, 2002). Ver também: Spinelli (2015).

88 Seção 602, (4). Tradução livre de: "the person is expelled as a member pursuant to the operating agreement." (THE UNITED STATES OF AMERICA, 2017, online).

\section{REFERÊNCIAS}

AMARAL, José Romeu Garcia do. Ensaio sobre o regime jurídico das debêntures. 2014. 269 f. Dissertação (Mestrado em Direito Comercial) - Faculdade de Direito, Universidade de São Paulo, São Paulo, 2014.

ANGELICI, Carlo; FERRI, Giovanni. Manuale di Diritto Commerciale. 12. ed. Torino: Utet Giuridica, 2006.

AULETTA, Giuseppe; SALANITRO, Niccolò. Diritto Commerciale. Milano: Giuffrè, 2003.

BABRI FILHO, Celso. Dissolução parcial de sociedades limitadas. Belo Horizonte: Mandamentos, 2004.

BAGLEY, William D.; WHYNOTT, Philip P. The limited liability company. Los Angeles: James Publishing, 1994. 
BORGES, João Eunápio. Curso de direito comercial terrestre. Rio de Janeiro: Forense, 1959. v. 1.

BURNHAM, William. Introduction to the law and legal system of the United Sates. 5. ed. Saint Paul: Thompson Reuters, 2006.

BRASIL. Decreto-Lei n. ${ }^{0}$ 5.452, de $1^{\circ}$ de maio de 1943. Aprova a Consolidação das Leis do Trabalho. Presidência da República, Brasília, DF, 1943.

. Constituição (1988). Constituição da República Federativa do Brasil de 1988.

Presidência da República, Brasília, DF, 1988. Disponível em: < http://www.planalto.gov. br/ccivil_03/Constituicao/Constituicao.htm >. Acesso em: 10 abr. 2017.

. Lei no 10.406, de 10 de janeiro de 2002. Institui o Código Civil. Presidência da República, Brasília, DF, 2002. Disponível em: < http://www.planalto.gov.br/ccivil_03/ leis/2002/110406.htm >. Acesso em: 10 abr. 2017.

. Comissão de Valores Mobiliários - CVM. Instrução Normativa nº 480/2009.

2009. Disponível em: <http://www.cvm.gov.br/legislacao/inst/inst480.html>. Acesso em: 10 abr. 2017.

. Câmara dos Deputados. Projeto de Lei no 1.572, de 14 de junho de 2011. Institui o Código Comercial. Autor: Deputado Vicente Cândido. Câmara dos Deputados, Brasília, 14 jun. 2011.

. Senado Federal. Projeto de Lei no 487, de 22 de novembro de 2013. Reforma o Código Comercial. Autor: Senador Renan Calheiros. Senado Federal, Brasília, 22 nov. 2013.

. Comissão de Valores Mobiliários - CVM. Instrução Normativa nº 566/2015. 2015a. Disponível em: <http://www.cvm.gov.br/legislacao/inst/inst566.html>. Acesso em: 10 abr. 2017.

. Lei no 13.105, de 16 de março de 2015. Código de Processo Civil. Presidência da República, Brasília, DF, 16 de março de 2015b.

. Comissão de Valores Mobiliários - CVM. Instrução Normativa n ${ }^{\circ}$ 578/2016.

2016. Disponível em: < http://www.cvm.gov.br/legislacao/inst/inst391.html>. Acesso em: 10 abr. 2017.

. Departamento de Registro Empresarial e Integração (DREI). Instrução Normativa $\mathrm{n}^{\circ}$ 38, de 2 de março de 2017. DOU, 6 mar. 2017. Disponível em: <http://www.normaslegais.com.br/legislacao/instrucao-normativa-drei-38-2017.htm >. Acesso em: 30 mar. 2017.

BREWER, Cassady V. Seven Ways to Strengthen and Improve the L3C. Regent University Law Review, Virginia Beach, v. 25, n. 2, p. 329-350, 2013. 
BULGARELLI, Waldirio. Anotações sobre o acordo de cotistas. Revista de Direito Mercantil, Industrial, Econômico e Financeiro, São Paulo, v. 34, n. 98, p. 44-49, abr./jun. 1995.

COELHO, Inocêncio Mártires; BRANCO, Paulo Gustavo Gonet. Curso de Direito Constitucional. 2. ed. São Paulo: Saraiva, 2008.

CRISÓSTOMO, André Fernandes. Debêntures: distribuição privada por sociedade limitada na recuperação da empresa. 2011. 270 f. Dissertação (Mestrado em Direito Empresarial) - Faculdade de Direito, Universidade Federal de Minas Gerais, Belo Horizonte, 2011.

DINIZ, Gustavo Saad. A primeira década do Código Civil e alguns problemas para as organizações empresariais. Revista dos Tribunais, São Paulo, v. 101, n. 917, p. 207-222. Mar. 2012.

EASTERBROOK., Frank H.; FISCHEL, Daniel R. The Economic Structure of Corporate Law. Massachusetts: Harvard University Press, 1991.

ESTADOS UNIDOS DA AMÉRICA. Constituição do Estados Unidos da América. Convenção Constitucional, Pensilvânia, Artigo I, Seção 8, 4 de março de 1789.

. Delaware Limited Liability Company Act - DLLCA. Disponível em: < http://delcode.delaware.gov/title6/c018/sc02/index.shtml>. Acesso em: 30 mar. 2017.

FARNSWORTH, E. Allan. An introduction to the legal system of the United Sates. 4. ed. Oxford: Oxford University Press, 2010.

FERREIRA, Waldemar. Tratado de direito comercial: primeiro volume: o estatuto histórico e dogmático do direito comercial. São Paulo: Saraiva, 1960. v. I.

FONSECA, Priscila Maria Pereira Corrêa da. Dissolução parcial, retirada e exclusão de sócio. 5. ed. São Paulo: Atlas, 2012.

FRANKLIN, Eric H. A rational approach to business entity choice. Kansas Law Review, Lawrence, v. 64, n. 1, p. 573-662, 2016.

GILSON, Ronald J. Globalizing corporate governance: convergence of form or function. Columbia Law School Working Paper, n. 174, p. 1-35, May 2000.

GIRNYS, Raymond P. Regulation LLC. New York Law School Law Review, Los Angeles, v. 56, n. 4, p. 1537-1565, 2011/2012.

GOFORHT, Carol. Too many cooks spoil the cake, and too many statutes spoil the LLC: a plea for uniformity. Southwestern Law Review, Los Angeles, v. 46, n. 1, p. 63-121, 2016.

GOMTSIAN, Suren. The governance of publicly traded limited liability companies. Delaware Journal of Corporate Law, Wilmington, v. 40, n. 1, p. 207-279, 2015. 
. Private ordering of exit in limited liability companies: theory and evidence from business organization contracts. American Business Law Journal, New Jersey, v. 53, n. 4, p. 677-744, 2016.

GONÇALVES NETO, Alfredo de Assis. Sociedade de Advogados. 4. ed. São Paulo: Lex Editora, 2006.

. Direito de Empresa. 4. ed. São Paulo: Revista dos Tribunais, 2012.

HAMILL, Susan Pace. The origins behind the limited liability company. Ohio State Law Journal, Columbus, Ohio State University, v. 59, n. 5, p. 1459-1522, Mar. 1998.

HAMILTON, Robert W.; MACEY, Jonathan R.; MOLL, Douglas K. The Law of Business Organizations: cases, materials and problems. 12. ed. Saint Paul: Thomson Reuters, 2014.

HANSMANN, Henry; KRAAKMAN, Reinier. The end of history for corporate law. Yale Law School Working Paper, n. 235, p. 1-37, Jan. 2000.

HANSMANN, Henry; KRAAKMAN, Reinier; SQUIRE, Richard. The new business entities in evolutionary perspective. University of Illinois Law Review, Urbana-Champaign, v. 5, n. 1, p. 5-14, Feb. 2005.

HEMINWAY, Joan MacLeod. The ties that bind: 1lc operating agreements as binding commitments. SMU Law Review, Dallas, v. 68, n. 3, p. 811-830, 2015.

HORTON, Brent J. Modifying Fiduciary Duties in Delaware: Ten Years of Decisional Law. Delaware Journal of Corporate Law, Wilmington, v. 40, n. 3, p. 921-970, 2016. INSTITUTO BRASILEIRO DE PLANEJAMENTO E TRIBUTAÇÃO. Censo das Empresas Brasileiras 2012. 2012. Disponível em: <http://www.ibpt.com.br/noticia/372/ Censo-das-Empresas-Brasileiras-2012>. Acesso em: 20 mar. 2017.

KEATINGE, Robert R. et al. The limited liability company: a study of the emerging entity. The Business Lawyer, Chicago, v. 47, n. 2, p. 375-460, Feb. 1992.

KLEIN, William A.; COFFEE, John C.; PARTNOY JUNIOR, Frank. Business organization and finance: legal and economic principles. 11. ed. New York: Foundation Press, 2010.

KLEINBERGER, Daniel S. A Myth Deconstructed: "The Emperor's New Clothes" on the Low-Profit Limited Liability Company. Delaware Journal of Corporate Law, Wilmington, v. 35, n. 3, p. 879-910, 2010.

LOBO, Jorge. Sociedades Limitadas. Rio de Janeiro: Forense, 2004. v. 1.

MILLER, Meredith R. The New York limited liability company law at twenty: past, present \& future. Touro Law Review, Long Island, v. 31, n. 3, p. 403-410, 2015. 
MILLER, Meredith R.; ANTONUCCI, Yvonne L. Default Rules and Fiduciary Duty Waivers in Alternative Entities: Policy Issues and Empirical Insights. The Journal of Corporation Law, Iowa, v. 42, n. 1, p. 147-222, 2016.

PARENTONI, Leonardo; GONTIJO, Bruno Miranda. Competência Legislativa em Direito Societário: Sistemas brasileiro, norte-americano e comunitário europeu. Revista de Informação Legislativa, Brasília, ano 53, n. 210, p. 239-265, abr./jun. 2016.

PARENTONI, Leonardo; MIRANDA, Jacqueline Delgado. Cotas sem direito de voto na sociedade limitada: panorama brasileiro e norte-americano. Revista Eletrônica do Curso de Direito UFSM, Santa Maria, v. 11, n. 2, p. 702-733, Aug. 2016.

PARENTONI, Leonardo; LIMA, Henrique Cunha Souza. Exclusão extrajudicial de cotista minoritário: aspectos controversos do art. 1.085 do Código Civil. Revista da Faculdade de Direito da UFMG, Belo Horizonte, v. 69, p. 311-344, jul./dez. 2016.

PARENTONI, Leonardo. O Conceito de Empresa no Código Civil de 2002. Revista Forense, Rio de Janeiro, v. 388, p. 133-151, 2006.

PARENTONI, Leonardo; FÉRES, Marcelo Andrade. Sociedade Anônima Fechada em Perspectiva. Revista de Direito das Sociedades e dos Valores Mobiliários, São Paulo, ano 1, n. 4, p. 37-64, nov. 2016.

PRADO, Roberta Nioace et al. Determinantes estratégicas na escolha do tipo societário: LTDA ou S.A.? In: PRADO, Roberta Nioac; PEIXOTO, Daniel Monteiro; DE SANTI, Eurico Marcos Diniz (Coord.). Estratégias Societárias, Planejamento Tributário e Sucessório. 2. ed. São Paulo: Saraiva, 2011.

RIBSTEIN, Larry E. An Analysis of the Revised Uniform Limited Liability Company Act. Virginia Law \& Business Review, Charlottesville, v. 3, n. 1, p. 36-80, 2008.

RIBSTEIN, Larry E. Limited liability unlimited. George Mason University Working Paper, n. 98, p. 1-41, May 1998. Available at: < https://papers.ssrn.com/sol3/papers. cfm?abstract_id=92188>. Access: 30 Mar. 2017.

RIBSTEIN, Larry E. The rise of the uncorporarion. 12. ed. New York: Oxford University Press, 2010.

RIBSTEIN, Larry E; KEATINGE, Robert R. Ribstein and keating on limited liability companies. 2. ed. Saint Paul: Thomson Reuters, 2016. v. I.

RODRIGUES, Nina Tricia Disconzi; FERRER, Alexandre de Moura Bonini; SIMÕES, Isadora Scherer. EIRELI: Constituição e reflexões acerca do Projeto de Lei do Senado 96/2012. Revista de Informação Legislativa, Brasília, ano 53, n. 211, p. 227-252, set. 2016.

ROE, Mark J. Delaware and Washington as Corporate Lawmakers. The Delaware Journal of Corporate Law, Wilmington, v. 34, n. 1, p. 1-34, 2009. 
SMITH, Kenya J. H. Papa's Brand New Bag: The Need for IRS Recognition of an Independent Nonprofit Limited Liability Company (NLLC). Marquette Law Review, Milwaukee, v. 98, n. 4, p. 1695-1728, 2015.

SPINELLI, Luis Felipe. Exclusão de sócio por falta grave na sociedade limitada. São Paulo: Quartier Latin, 2015.

THE UNITED STATES OF AMERICA. Limited Liability Company Center. Available at: <http://www.limitedliabilitycompanycenter.com/>. Access: 2 Dec. 2015. The Uniform Law Commission. Revised Uniform Limited Liability Company Act: RULLCA. Available at: <http://www.uniformlaws.org/> . Access: 25 Mar. 2017. WALKER, David S. A Consideration of an LLC for a 501 (c) (3) Nonprofit Organization. William Mitchell Law Review, Saint Paul, v. 38, n. 2, p. 627-677, 2012.

WILSON, Elaine Waterhouse. Better Late than Never: Incorporating LLCs into Section 4943. Akron Law Review, Akron, v. 48, n. 3, p. 485-546, 2015. 